
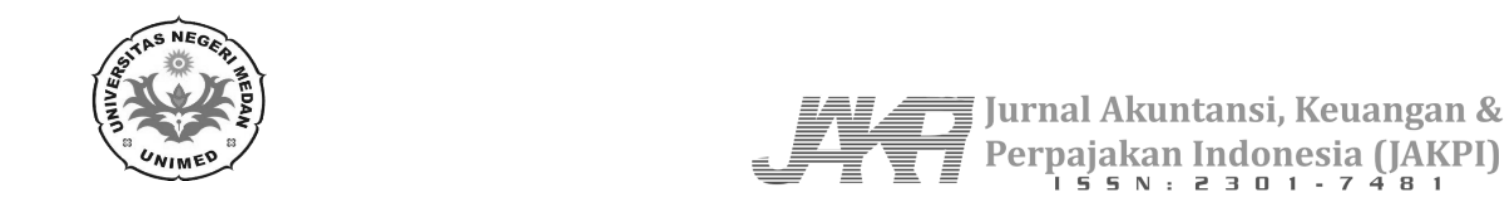

\title{
Pengaruh Profitabilitas, Pajak, Mekanisme Bonus, Kepemilikan Asing, Debt Covenant Dan Intangible Assets Terhadap Transfer Pricing (Studi Empiris Pada Perusahaan Manufaktur Yang Terdaftar Di Bei Tahun 2015 - 2017)
}

\author{
Destriana Br Ginting ${ }^{1}$, Yulita Triadiarti ${ }^{2}$, Erny Luxy Purba ${ }^{3}$ \\ Universitas Negeri Medan \\ destridean@yahoo.com
}

\begin{abstract}
Abstrak : The problem in this research is Transfer pricing is a company policy in determining the price of transactions between division members in a multinational company, which makes it easy for companies to adjust internal prices for goods, services and intangible assets traded so as not to create prices that are too low or too high. But in practice transfer pricing is one of the efforts of corporate tax planning with the aim of minimizing the tax burden that must be paid by engineering transfer prices between companies that have special relationships. The population of this research is 143 manufacturing companies listed on the Indonesia Stock Exchange in 2015-2017. The research sample was 16 companies with purposive sampling method, with quantitative research types. The data used is secondary data, namely the company's financial statements obtained from www.idx.co.id. The data analysis technique used is descriptive statistics, classic assumption test, multiple regression analysis, coefficient of determination, F-statistical test, and t-statistical test. The data analysis technique used is descriptive statistics, classic assumption test, multiple regression analysis, coefficient of determination, F-statistical test, and t-statistical test. The dependent variable in this study is Transfer Pricing which is Proxied with RTP ( Related Party Transaction). Independent variables used are Profitability, Tax, Bonus Mechanisms, Foreign Ownership, Debt Covenant and Intangible Assets . The analytical method used in this study is multiple regression analysis with SPSS 20. Based on the results of this study simultaneously Profitability, Taxes, Mechanisms of Bonuses, Foreign Ownership, Debt Covenants and Intangible Assets no significant effect on Transfer Pricing . Partially Only Intangible Assets that affect Transfer Pricing. The conclusion of this study is that Profitability has no effect on Transfer Pricing, Tax has no effect on Transfer Pricing, Bonus Mechanism has no effect on Transfer Pricing, Foreign Ownership has no effect on Transfer Pricing, Debt Covenant has no effect on Transfer Pricing and Intangible Assets Influence Transfer Pricing.
\end{abstract}

Keywords: Transfer Pricing, profitability, Taxes, Bonus Mechanisms, Foreign Ownership, Debt Covenant , Intangible Assets 
Pengaruh Profitabilitas, Pajak, Mekanisme Bonus, Kepemilikan Asing, Debt Covenant Dan Intangible Assets Terhadap Transfer Pricing (Studi Empiris Pada Perusahaan Manufaktur Yang Terdaftar Di Bei Tahun 2015 - 2017)

\section{Pendahuluan}

Perkembangan ekonomi yang terjadi saat ini, memberikan suatu pengaruh yang besar bagi pola bisnis dan sikap para pelaku bisnis, yang disebabkan oleh globalisasi sehingga perekonomian berkembang tanpa mengenal batas negara. Hal memberi kebebasan bagi perusahaan dari penjuru dunia untuk memperluas atau mengembangkan aktivitas bisnisnya di berbagai negara yang dinilai memiliki potensi keuntungan yang lebih menjanjikan untuk aktivitas penjualan, pembelian bahan baku, pemberian jasa dan lain sebagainya yang terjadi antar divisi perusahaan dalam satu grup kepemilikan (Anisyah, 2018).

Faktor lain yang mempengaruhi perusahaan multinasional melakukan transfer pricing adalah kepemilikan asing. Kepemilikan saham asing merupakan proporsi saham biasa perusahaan yang dimiliki oleh perorangan, badan hukum, pemerintah serta bagian-bagiannya yang berstatus luar negeri. Banyak perusahaan di Asia termasuk Indonesia memiliki struktur kepemilikan yang terkonsentrasi. Dalam perusahaan yang kepemilikannya terkonsentrasi, pemegang saham pengendali memiliki lebih banyak pengaruh terhadap perusahaan seperti akses informasi, pengawasan dan pengendalian terhadap aktivitas bisnis perusahaan (Tiwa dkk, 2017).

Debt covenant juga turut mempengaruhi keputusan manajemen untuk melakukan transfer pricing. Sesuai dengan the debt covenant hypothesis memprediksi bahwa manajer ingin meningkatkan laba dan aktiva untuk mengurangi biaya kontrak utang ketika perusahaan memutuskan perjanjian utangnya (Fatmariani, 2013). Perusahaan yang memiliki rasio hutang yang tinggi akan berusaha menghindari terjadinya pelanggaran kontrak hutang dengan cara memilih metode akuntansi yang meningkatkan laba perusahaan.

Faktor lainnya yang mempengaruhi transfer pricing adalah intangible assets (Aset Tak Berwujud), dalam PSAK 19 intangible assets didefinisikan sebagai suatu aktiva yang pada umumnya memiliki masa manfaat yang panjang dan tidak mempunyai bentuk fisik serta memiliki kegunaan dalam kegiatan operasi perusahaan (Anisyah, 2018).

Dikarenakan belum tersedianya aturan yang baku, perkara pemeriksaan transaksi transfer pricing sering kali dimenangkan oleh wajib pajak dalam pengadilan pajak sehingga perusahaan multinasional semakin termotivasi untuk melakukan transfer pricing. Penelitian yang intens dan berkelanjutan mengenai transfer pricing akan sangat membantu otoritas perpajakan dalam menyusun praturan yang mampu mengontrol aktivitas transfer pricing di kalangan perusahaan multinasional yang memiliki hubungan istimewa, sehingga penerimaan pajak negara menjadi maksimal (Tiwa dkk, 2017).

Tujuan Penelitian yang ingin dicapai adalah untuk menguji pengaruh Profitabilitas, Pajak, Mekanisme Bonus, Kepemilikan Asing, Debt Covenant Dan Intangible Assets terhadap Transfer Pricing pada perusahaan manufaktur yang terdaftar di BEI.

\section{Landasan Teori Dan Pengembangan Hipotesis Teori Keagenan}

Teori keagenan merupakan konsep yang menjelaskan hubungan kontraktual antara principal dan agents. Pihak principals adalah pihak yang memberikan mandat kepada pihak lain, yaitu agent, untuk melakukan semua kegiatan atas nama principals dalam kapasitasnya sebagai pengambil keputusan (Jensen dan Meckling, 1976). Pemilik perusahaan (principals) menyediakan fasilitas dan dana untuk kebutuhan operasi perusahaan. Manajemen (agen) sebagai pengelola kewajiban untuk mengelola perusahaan sebagaimana dipercayakan principals untuk meningkatkan kemakmuran principals. Manajemen (agen) juga mempunyai kewajiban untuk melaporkan dan memberi informasi kepada pemilik (principals). Namun terkadang manajemen tidak melaporkan keadaan perusahaan sesuai dengan keadaan perusahaan yang sebenarnya.

\subsection{Pengembangan Hipotesis}

Profitabilitas merupakan suatu indikator kinerja yang dilakukan manajemen dalam mengelola kekayaan perusahaan yang ditunjukkan oleh laba yang dihasilkan, atau dapat dikatakan kemampuan perusahaan dalam mencari keuntungan. Pendapatan sebelum pajak perusahaan yang tinggi dianggap akan menghindari pembayaran secara proporsional. Perusahaan ingin mendapatkan keuntungan yang setinggi-tingginya namun tidak ingin membayarkan pajak yang besar kepada negara Deanti (2017). Maka perusahaan akan cenderung mencari cara untuk menghindari hal tersebut, salah satunya dengan 
Pengaruh Profitabilitas, Pajak, Mekanisme Bonus, Kepemilikan Asing, Debt Covenant Dan Intangible Assets Terhadap Transfer Pricing (Studi Empiris Pada Perusahaan Manufaktur Yang Terdaftar Di Bei Tahun 2015 - 2017)

melakukan transfer pricing. Apabila Profitabilitas perusahaan tinggi, maka indikasi terjadinya Transfer Pricing akan lebih rendah, namun apabila Apabila Profitabilitas perusahaan rendah, maka indikasi terjadinya Transfer Pricing akan lebih tinggi. Oleh karena itu, terdapat pengaruh antara profitabilitas dengan transfer pricing.

Pembayaran pajak merupakan kewajiban bagi setiap warga negara yang telah memenuhi kriteria wajib pajak di negara manapun. Alangkah baiknya para wajib pajak membayarkan pajak nya tepat waktu dan sesuai dengan jumlahnya. Akan tetapi, pembayaran pajak dengan nominal yang besar dirasa membebani para wajib pajak karena dianggap tidak ada manfaat yang dirasakan secara langsung. Agar dapat mengurangi biaya Debt covenant, sering kali perusahaan selalu berusaha membuat laba perusahaan dalam kondisi baik agar para kreditur mau meminjamkan uangnya, yang mana didalam setiap perjanjian akan memunculkan syarat-syarat tertentu atau aturan-aturan yang tidak boleh di langgar agar melancarkan perjanjian Debt covenant tersebut dan tidak terjadi yang namanya denda atas pelanggaran kontrak hutang. Seperti yang dikatakan dalam Debt covenant hypothesis, yang memprediksikan bahwa manajer ingin meningkatkan laba dan aktiva untuk mengurangi biaya Debt covenant ketika perusahaan memutuskan perjanjian utangnya. Oleh karena itu, untuk dapat meningkatkan laba perusahaan, manajemen akan cenderung untuk melakukan transfer pricing agar mengurangi biaya dari Debt covenant nya. Oleh karena itu, terdapat pengaruh antara debt covenant dengan transfer pricing.

Berdasarkan landasan teori yang telah dikemukakan di atas, maka penulis menggambarkan kerangka berpikir sebagai berikut :

\section{Gambar 1}

Kerangka Berpikir

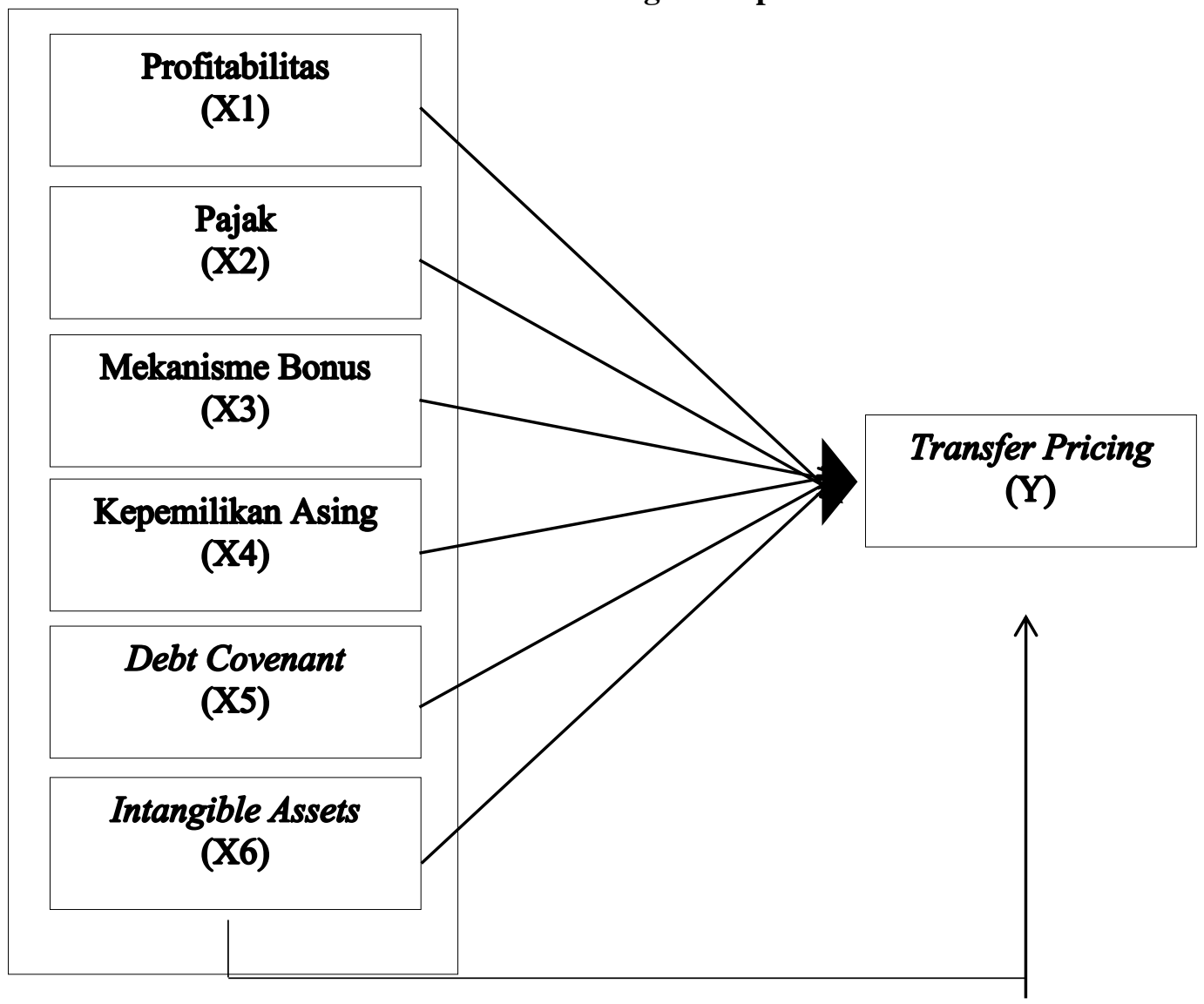

H1 : Profitabilitas berpengaruh terhadap Transfer Pricing pada perusahaan manufaktur yang terdaftar di BEI.

H2 : Pajak berpengaruh terhadap Transfer Pricing pada perusahaan manufaktur yang terdaftar di BEI.

H3 : Mekanisme Bonus berpengaruh terhadap Transfer Pricing pada perusahaan manufaktur yang terdaftar di BEI. 
Pengaruh Profitabilitas, Pajak, Mekanisme Bonus, Kepemilikan Asing, Debt Covenant Dan Intangible Assets Terhadap Transfer Pricing (Studi Empiris Pada Perusahaan Manufaktur Yang Terdaftar Di Bei Tahun 2015 - 2017)

H4 : Kepemilikan Asing berpengaruh terhadap Transfer Pricing pada perusahaan manufaktur yang terdaftar di BEI.

H5 : Debt Covenant berpengaruh terhadap Transfer Pricing pada perusahaan manufaktur yang terdaftar di BEI.

H6 : Intangible Assets berpengaruh terhadap Transfer Pricing pada perusahaan manufaktur yang terdaftar di BEI.

H7 : Profitabilitas, pajak, Mekanisme Bonus, Kepemilikan Asing, Debt Covenant dan Intangible Assets berpengaruh terhadap Transfer Pricing pada perusahaan manufaktur yang terdaftar di BEI.

\section{Metode Penelitian}

\subsection{Populasi dan Sampel}

Populasi yang digunakan dalam penelitian ini adalah seluruh perusahaan manufaktur yang terdaftar di Bursa Efek Indonesia (BEI) pada tahun 2015-2017. Pengambilan sampel dalam penelitian ini menggunakan metode purposive sampling. Pemilihan sampel dengan purposive sampling dilakukan dengan tujuan untuk memperoleh sampel yang representative berdasarkan kriteria tertentu. Penentuan kriteria diperlukan untuk menghindari timbulnya kesalahan dalam penentuan sampel penelitian. Sampel penelitian yang diambil berdasarkan kriteria-kriteria sebagai berikut :

1. Perusahaan manufaktur yang terdaftar di BEI selama tahun 2015-2017 dan telah di audit.

2. Perusahaan sampel yang dikendalikan oleh perusahaan asing dengan kepemilikan $25 \%$ atau lebih. Hal ini sesuai dengan UU Nomor 36 tahun 2008 tentang pajak penghasilan.

3. Perusahaan yang menyajikan laporan keuangannya dalam satu jenis mata uang yaitu rupiah.

4. Perusahaan mengungkapkan transaksi transfer pricing dalam laporan keuangannya melalui piutang usaha pihak berelasi.

5. Perusahaan tidak mengalami kerugian selama periode pengamatan.

\subsection{Defenisi Operasional Dan Pengukuran Variabel 3.2.1 Transfer Pricing}

Transfer Pricing merupakan harga yang terkandung pada setiap produk atau jasa dari satu divisi ke divisi lain dalam perusahaan yang sama atau antar perusahaan yang mempunyai hubungan istimewa (Yuniasih, 2012). Transfer pricing dalam penelitian ini diproksikan dengan presentasi piutang perusahaan yang berafiliasi (Related Party Transaction) terhadap total piutang perusahaan.

$$
R P T=\frac{\text { Piutang Pihak Berelasi }}{\text { Total Piutang Perusahaan }} \times 100 \%
$$

\subsubsection{Profitabilitas}

Profitabilitas merupakan rasio untuk menilai kemampuan perusahaan dalam mencari keuntungan (Kasmir, 2013). Profitabilitas dalam penelitian ini diproksikan dengan alat ukur Return On Assets (ROA) dengan rumus :

$$
\mathrm{ROA}=\frac{\text { Laba Setelah Pajak }}{\text { Total Aset }} \times 100 \%
$$

\subsubsection{Pajak}

Pajak adalah iuran wajib dari rakyat kepada negara dengan tidak menerima imbalan jasa secara langsung berdasarkan undang-undang, untuk membiayai pengeluaran-pengeluaran umum. Besaran Pajak yang dibayarkan oleh perusahaan dapat dilihat dari perhitungan beban pajak dibagi dengan laba sebelum pajak. Pajak dalam penelitian ini diproksikan dengan Effective Tax Rate.

$$
E T R=\frac{\text { Beban Pajak }}{\text { Laba Sebelu Pajak }}
$$

\subsubsection{Mekanisme Bonus}

Mekanisme bonus adalah kompensasi tambahan atau penghargaan yang diberikan kepada pegawai atas keberhasilan pencapaian tujuan-tujuan yang di targetkan perusahaan (Sukma, 2018). Dalam hal ini, Mekanisme bonus diukur berdasarkan presentase pencapaian laba bersih tahun $\mathrm{t}$ terhadap laba bersih tahun t-1 (Hartati dkk, 2015). Mekanisme bonus diproksikan dengan index trend laba bersih (Irpan, 2011) : 
Pengaruh Profitabilitas, Pajak, Mekanisme Bonus, Kepemilikan Asing, Debt Covenant Dan Intangible Assets Terhadap Transfer Pricing (Studi Empiris Pada Perusahaan Manufaktur Yang Terdaftar Di Bei Tahun 2015 - 2017)

$$
\text { Mekanisme Bonus }=\frac{\text { laba bersih tahun } \mathrm{t}}{\text { Laba bersih tahun } \mathrm{t}-1} \times 100 \%
$$

\subsubsection{Kepemilikan Asing}

Kepemilikan saham oleh pihak asing adalah kepemilikan saham yang dimiliki oleh pihakpihak baik individu maupun institusional baik yang menggunakan modal asing sepenuhnya maupun yang berpatungan dengan pihak penanam modal dalam negeri. Kepemilikan asing dalam penelitian ini diproksikan dengan :

$$
\text { Kepemilikan Asing }=\frac{\text { jumlah kepemilikan saham asing }}{\text { total saham beredar }} \times 100 \%
$$

\subsubsection{Debt Covenant}

Debt Covenant merupakan kontrak yang ditujukan pada peminjam oleh kreditur untuk membatasi aktivitas yang mungkin merusak nilai pinjaman dan recovery pinjaman (Pambudi,2017). Debt covenant di proksikan dengan rasio hutang menggunakan Debt to Equity Ratio (DER) (Pramana, 2014) :

$$
D E R=\frac{\text { Total Hutang }}{\text { Modal Saham }} \times 100 \%
$$

\subsubsection{Intangible Assets}

Dalam PSAK No. 19 Pasal 17 (2015), aset tidak berwujud (intangible assets) adalah suatu aktiva yang pada umumnya memiliki masa manfaat yang panjang dan tidak mempunyai bentuk fisik serta memiliki kegunaan dalam kegiatan operasi perusahaan dan penggunaannya tidak untuk dijual kembali. Pengukuran menggunakan variabel dummy, dimana jika perusahaan menyajikan Intangible Assets dalam laporan keuangannya, maka skornya adalah 1. Jika tidak, maka skornya adalah 0 (Trisnajuna dan Sisdyani, 2015)

\subsection{Metode Analisa Data}

Pengujin hipotesis dalam penelitian ini menggunakan model regresi linear berganda. Pengujian hipotesis bertujuan untuk melihat pengaruh profitabilitas, pajak, mekanisme bonus, kepemilikan asing, debt covenant dan intangible assets terhadap transfer pricing. Persamaan model regresi dalam penelitian ini adalah sebagai berikut :

Keterangan :

$$
\mathrm{TP}=\alpha+\beta 1 \mathrm{~PB}+\beta 2 \mathrm{P}+\beta 3 \mathrm{MB}+\beta 4 \mathrm{KA}+\beta 5 \mathrm{DC}+\beta 6 \mathrm{IA}+e
$$

$$
\begin{array}{ll}
\mathrm{TP} & =\text { Transfer Pricing } \\
\mathrm{PB} & =\text { Profitabilitas } \\
\mathrm{P} & =\text { Pajak } \\
\mathrm{MB} & =\text { Mekanisme Bonus } \\
\mathrm{KA} & =\text { Kepemilikan Asing } \\
\mathrm{DC} & =\text { Debt Covenant } \\
\mathrm{IA} & =\text { Intangible Assets } \\
\alpha & =\text { Konstanta } \\
e & =\text { Error } \\
\beta & =\text { Koefisien }
\end{array}
$$

\section{Hasil Penelitian Dan Pembahasan 4.1. Analisis Statistik Deskriptif}

Tabel 1

Hasil Statistik Deskriptif

\begin{tabular}{lccccc}
\hline \multicolumn{7}{c}{ Descriptive Statistics } & & \\
\hline & $\mathrm{N}$ & Minimum & Maximum & Mean & Std. Deviation \\
\hline Profitabilitas & 48 &, 00 &, 17 &, 0730 &, 04454 \\
Pajak & 48 &, 07 & 2,05 &, 3265 &, 28743 \\
Mekanisme Bonus & 48 &, 10 & 53,73 & 2,1070 & 7,62541 \\
Kepemilikan Asing & 48 &, 21 &, 59 &, 3936 &, 11386 \\
\hline
\end{tabular}


Pengaruh Profitabilitas, Pajak, Mekanisme Bonus, Kepemilikan Asing, Debt Covenant Dan Intangible Assets Terhadap Transfer Pricing (Studi Empiris Pada Perusahaan Manufaktur Yang Terdaftar Di Bei Tahun 2015 - 2017)

\begin{tabular}{|c|c|c|c|c|c|}
\hline Debt Covenant & 48 & ,04 & 46,44 & 7,6438 & 10,78116 \\
\hline Intangible Assets & 48 &, 00 & 1,00 & ,4792 & ,50485 \\
\hline Transfer Pricing & 48 &, 00 & ,98 & ,3398 & ,35985 \\
\hline Valid N (listwise) & 48 & & & & \\
\hline
\end{tabular}

\subsection{Analisis Pengujian Heterokedastisitas}

Tabel 2

Hasil Pengujian Heterokedastisitas

\begin{tabular}{|c|c|c|c|c|c|c|}
\hline \multicolumn{7}{|c|}{ Coefficients $^{\mathrm{a}}$} \\
\hline \multirow{2}{*}{\multicolumn{2}{|c|}{ Model }} & \multicolumn{2}{|c|}{ Unstandardized Coefficients } & \multirow{2}{*}{$\begin{array}{c}\begin{array}{c}\text { Standardized } \\
\text { Coefficients }\end{array} \\
\text { Beta } \\
\end{array}$} & \multirow[t]{2}{*}{$\mathrm{t}$} & \multirow[t]{2}{*}{ Sig. } \\
\hline & & $\mathrm{B}$ & Std. Error & & & \\
\hline \multirow{7}{*}{1} & (Constant) & ,438 &, 116 & & 3,780 & ,000 \\
\hline & Profitabilitas & ,207 & ,699 &, 051 & ,296 & ,769 \\
\hline & Pajak &,- 084 & ,103 &,- 135 &,- 817 & ,419 \\
\hline & Mekanisme Bonus &,- 005 & ,004 &,- 214 & $-1,401$ & , 169 \\
\hline & Kepemilikan Asing &,- 352 & ,275 &,- 223 & $-1,281$ & 207 \\
\hline & Debt Covenant & $-7,303 \mathrm{E}-005$ & ,003 &,- 004 &,- 026 & ,980 \\
\hline & Intangible Assets &,- 020 & 059 &,- 057 &,- 344 & ,733 \\
\hline
\end{tabular}

a. Dependent Variable: ABS_RES1

\subsubsection{Uji Autokorelasi}

Tabel 3

Hasil Uji Autokorelasi

Runs Test

Test Value

Unstandardized Residual

Cases < Test Value

$-07237$

Cases $>=$ Test Value

Total Cases

Number of Runs

$\mathrm{Z}$

Asymp. Sig. (2-tailed)

4.1.4 Analisis Regresi Berganda

Tabel 4

Hasil Uji Regresi Berganda

\begin{tabular}{llcc}
\hline Model & \multicolumn{2}{c|}{ Unstandardized Coefficients } \\
\cline { 2 - 3 } & (Constant) & B & Std. Error \\
\hline Profitabilitas &, 547 &, 221 \\
& Pajak & 1,200 & 1,337 \\
1 & Mekanisme Bonus &,- 211 &, 197 \\
& Kepemilikan Asing &,- 006 &, 007 \\
& Debt Covenant &,- 213 &, 525 \\
Intangible Assets &, 002 &, 005 \\
&,,- 297 &, 112 \\
\hline
\end{tabular}

Berdasarkan tabel diatas, maka persamaan regresi dapat dirumuskan sebagai berikut :

$$
\mathrm{TP}=0,547+1,200 \mathrm{~PB}-0,211 \mathrm{P}-0,006 \mathrm{MB}-0,213 \mathrm{KA}+0,002 \mathrm{DC}-0,297 \mathrm{IA}
$$


Pengaruh Profitabilitas, Pajak, Mekanisme Bonus, Kepemilikan Asing, Debt Covenant Dan Intangible Assets Terhadap Transfer Pricing (Studi Empiris Pada Perusahaan Manufaktur Yang Terdaftar Di Bei Tahun 2015 - 2017)

\subsubsection{Uji Parsial}

Tabel 5

Hasil Uji Parsial

Coefficients $^{\mathrm{a}}$

\begin{tabular}{llcc}
\hline \multicolumn{1}{c}{ Model } & Coefficients $^{\mathbf{a}}$ & Sig. \\
& & & \\
\hline & (Constant) & 2,472 &, 018 \\
& Profitabilitas &, 898 &, 375 \\
& Pajak & $-1,072$ &, 290 \\
& Mekanisme Bonus &,- 866 &, 391 \\
& Kepemilikan Asing &,- 407 &, 686 \\
Debt Covenant &, 303 &, 763 \\
& Intangible Assets & $-2,642$ &, 012 \\
\hline
\end{tabular}

\subsubsection{Uji Simultan (Uji Statistik F)}

Tabel 6

Hasil Uji Simultan (Statistk F)

\begin{tabular}{clccccc}
\hline \multicolumn{7}{c}{ ANOVA $^{\mathbf{a}}$} \\
\hline & Model & Sum of Squares & Df & Mean Square & F & Sig. \\
\hline \multirow{2}{*}{1} & Regression & 1,164 & 6 &, 194 & 1,616 &, $167^{\mathbf{b}}$ \\
& Residual & 4,922 & 41 &, 120 & & \\
& Total & 6,086 & 47 & & & \\
\hline
\end{tabular}

a. Dependent Variable: TRANSFER PRICING

b. Predictors: (Constant), Intangible Assets, Profitabilitas, Mekanisme Bonus, Debt Covenant, Pajak, Kepemilikan Asing

\subsection{Pembahasan Hasil Penelitian}

\subsubsection{Pengaruh Profitabilitas Terhadap Transfer Pricing}

Berdasarkan uji hipotesis t menunjukkan nilai variabel Profitabilitas menghasilkan nilai $\mathrm{T}_{\text {hitung }}$ $0,898<$ nilai $\mathrm{T}_{\text {tabel }} 2,01954(0,898>2,01954)$ dan nilai signifikansi $0,375>0,05$, yang berarti $\mathrm{H}_{1}$ ditolak, atau Profitabilitas tidak berpengaruh terhadap Transfer Pricing.

Alasan tidak berpengaruhnya profitabilitas Terhadap Transfer Pricing adalah dimana perusahaan yang mempunyai tingkat keuntungan yang besar atau pendapatan sebelum pajak yang tinggi akan mempunyai sumber pendanaan internal yang lebih besar pula sehingga memungkinkan perusahaan untuk cenderung memilih menggunakan modal sendiri yaitu dari dana internalnya terlebih dahulu, yang mana hal tersebut mengurangi keinginan perusahaan untuk melakukan Transfer Pricing demi meningkatkan nilai perusahaannya.

\subsubsection{Pengaruh Pajak Terhadap Transfer Pricing}

Berdasarkan uji hipotesis t menunjukkan nilai variabel Pajak menghasilkan nilai $\mathrm{T}_{\text {hitung }}$ $1,072<$ nilai $\mathrm{T}_{\text {tabel }} 2,01954(-1,072<2,01954)$ dan nilai signifikansi $0,290>0,05$, yang berarti $\mathrm{H}_{2}$ ditolak, atau Pajak tidak berpengaruh terhadap Transfer Pricing.

Hasil Penelitian ini tidak sejalan dengan teori keagenan yang menjelaskan bahwa masalahmasalah keagenan terjadi karena terdapat pihak-pihak yang memiliki perbedaan kepentingan namun saling bekerja sama dalam pembagian tugas yang berbeda. Konflik keagenan dapat merugikan pihak Principals (pemilik) karena pemilik tidak terlibat langsung dalam pengelolaan perusahaan sehingga tidak memiliki akses untuk mendapatkan informasi yang memadai.

\subsubsection{Pengaruh Mekanisme Bonus Terhadap Transfer Pricing}

Hasil uji t pada variabel Mekanisme Bonus menghasilkan nilai $\mathrm{T}_{\text {hitung }}-0,866<$ nilai $\mathrm{T}_{\text {tabel }}$ $2,01954(-0,866<2,01954)$ dan nilai signifikansi 0,391>0,05, yang berarti $\mathrm{H}_{3}$ ditolak, atau Mekanisme Bonus tidak berpengaruh terhadap Transfer Pricing. 
Pengaruh Profitabilitas, Pajak, Mekanisme Bonus, Kepemilikan Asing, Debt Covenant Dan Intangible Assets Terhadap Transfer Pricing (Studi Empiris Pada Perusahaan Manufaktur Yang Terdaftar Di Bei Tahun 2015 - 2017)

Nilai Indeks Tren Laba Bersih yang tinggi menunjukkan dari setiap laba di tahun berjalan lebih tinggi dibandingkan dengan laba tahun sebelumnya. Dalam penelitian ini nilai Indeks Tren Laba Bersih nya dapat dianggap cenderung stabil. Dengan nilai yang stabil ini menunjukkan perusahaan kurang tertarik dalam memanipulasi laba dan transfer pricing untuk memaksimalkan penerimaan bonus.

\subsubsection{Pengaruh Kepemilikan Asing Terhadap Transfer Pricing}

Hasil uji t pada variabel Kepemilikan Asing menghasilkan nilai $\mathrm{T}_{\text {hitung }}-0,407<$ nilai $\mathrm{T}_{\text {tabel }}$ $2,01954(-0,407<2,01954)$ dan nilai signifikansi $0,391>0,05$, yang berarti $\mathrm{H}_{4}$ ditolak, atau Kepemilikan Asing tidak berpengaruh terhadap Transfer Pricing.

Penjelasan yang dapat diberikan mengenai tidak berpengaruhnya kepemilikan asing terhadap penerapan transfer pricing adalah pemegang saham pengendali tidak melakukan transfer pricing dalam rangka ekspropriasi. Mengingat bahwa perusahaan yang diteliti adalah perusahaan yang memiliki kepemilikan asing di atas $25 \%$ yang memiliki kendali terhadap perusahaan cabang maupun anak tanpa hubungan istimewa berbentuk keluarga sedarah, maka segala keputusan dalam perusahaan berada di skala organisasional yang memerlukan kesepakatan dari direksi perusahaan sehingga melakukan ekpropriasi untuk memaksimalkan kesejahteraan pribadi menjadi tidak relevan.

\subsubsection{Pengaruh Debt Covenant Terhadap Transfer Pricing}

Hasil uji t pada variabel Debt Covnant menghasilkan nilai $\mathrm{T}_{\text {hitung }} 0,303<$ nilai $\mathrm{T}_{\text {tabel }} 2,01954$ $(0,303<2,01954)$ dan nilai signifikansi $0,763>0,05$, yang berarti $\mathrm{H}_{5}$ ditolak, atau Debt Covnant tidak berpengaruh terhadap Transfer Pricing.

Hasil penelitian ini tidak sejalan dengan teori Hipotesis Kontrak Hutang (the debt covenant hypotesis) yang menyatakan makin dekat suatu perusahaan terhadap pelanggaran pada akuntansi yang didasarkan pada kesepakatan utang, maka kecenderungannya adalah semakin besar kemungkinan manajer perusahaan memilih prosedur akuntansi dengan perubahan laba yang dilaporkan dari periode masa depan ke periode masa kini. Alasannya adalah laba yang dilaporkan yang makin meningkat akan menurunkan kelalaian teknis.

Alasan tidak berpengaruhnya Debt Covenant terhadap Transfer Pricing adalah laba perusahaan yang di laporkan perusahaan dalam tahun pengamatan penelitian ini meningkat dan stabil yang artinya akan menurunkan kelalaian teknis. Itulah sebabnya perusahaan tidak tertarik dalam melakukan Transfer Pricing.

\subsubsection{Pengaruh Intangible Assets Terhadap Transfer Pricing}

Hasil uji t pada variabel Intangible Assets menghasilkan nilai $\mathrm{T}_{\text {hitung }}-2,642>$ nilai $\mathrm{T}_{\text {tabel }} 2,01954$ $(-2,642>2,01954)$ dan nilai signifikansi $0,012<0,05$, nilai t negatif menunjukkan bahwa Intangible Assets mempunyai hubungan yang berlawanan arah dengan Transfer Pricing. Intangible Assets berpengaruh terhadap Transfer Pricing.

Berdasarkan hasil hasil analisis diatas maka hipotesis keenam pada penelitian ini dapat diterima, namun berpengaruh negatif, semakin tinggi nilai Intangible Assets yang dimiliki oleh perusahaan, maka semakin memperkecil kemungkinan terjadinya Transfer Pricing.

\subsubsection{Pengaruh Profitabilitas, Pajak, Mekanisme Bonus, Kepemilikan Asing, Debt Covenant dan Intangible Assets Terhadap Transfer Pricing}

Berdasarkan hasil dari pengujian SPSS dapat menunjukkan bahwa nilai F statistik sebesar 1,616 lebih kecil dari nilai $\mathrm{F}$ tabel yaitu sebesar 2,43 dengan nilai signifikan 0,167 lebih besar dari 0,05. Hal ini berarti variabel Profitabilitas, Pajak, Mekanisme Bonus, Kepemilikan Asing, Debt Covenant dan Intangible Assets secara simultan tidak berpengaruh signifikan terhadap variabel Transfer Pricing, dengan demikian $\mathrm{H}_{7}$ ditolak.

\section{Kesimpulan, Keterbatasan, Saran}

\subsection{Kesimpulan}

Variabel Profitabilitas, Pajak, Mekanisme Bonus, Kepemilikan Asing, Debt Covenant dan Intangible Assets secara simultan tidak berpengaruh signifikan terhadap variabel Transfer Pricing. 
Pengaruh Profitabilitas, Pajak, Mekanisme Bonus, Kepemilikan Asing, Debt Covenant Dan Intangible Assets Terhadap Transfer Pricing (Studi Empiris Pada Perusahaan Manufaktur Yang Terdaftar Di Bei Tahun 2015 - 2017)

\subsection{Keterbatasan}

Proksi lain dibutuhkan untuk menggambarkan intangible asset.

\subsection{Saran}

Berdasarkan hasil pembahasan yang telah dipaparkan diatas maka dapat diajukan saran kepada pihak-pihak yang bersangkutan sebagai berikut:

1. Penelitian ini hanya menghasilkan koefisien determinasi sebesar $19,1 \%$. Oleh karena itu masih ada variabel lain yang berpengaruh pada keputusan perusahaan untuk melakukan transfer pricing. Diharapkan kepada peneliti selanjutnya untuk mencari variabel lain yang dianggap lebih berpengaruh terhadap Transfer Pricing.

2. Penelitian selanjutnya diharapkan dapat menggunakan proksi lain untuk menggambarkan intangible assets sehingga memungkinkan adanya hasil yang berbeda jika menggunakan proksi lain.

3. Penelitian selanjutnya menggunakan sampel selain perusahaan manufaktur seperti seluruh sektor misalnya, untuk mengetahui seberapa besar transaksi transfer pricing yang terdapat di perusahaan selain sektor manufaktur.

\section{Daftar Pustaka}

Akbar, R. I., Akuntansi, J., Bisnis, F., Katolik, U., \& Mandala, W. (2015). Analisis Faktor-Faktor Yang Mempengaruhi Keputusan Transfer Pricing Pada Perusahaan Manufaktur.

Anisyah, Fitri. (2018). Pengaruh Beban Pajak, Intangible Assets, Profitabilitas, Tunneling Incentive, Dan Mekanisme Bonus Terhadap Transfer Pricing, 1, 1-14.

Arianandini, P. W. Dan Ramantha, I. W. Pengaruh Profitabilitas, Leverage, dan Kepemilikan Institusional pada Tax Avoidance. 2302-8556

Azis, Ziski. Dkk. 2016 Perpajakan Teori Dan Kasus.Medan : MADENATERA.

Cahyani , Krisanti Adi. (2014). Keluarga Dan Non Keluarga Berdasarkan Kepemilikan Ultimat, 26(2), 133-144.

Deanti, Laksmita Racmah. (2017). Pengaruh Pajak, Intangible Assets, Leverage, Profitabilitas dan Tunneling Incentive Terhadap Keputusan Transfer Pricing Perusahaan Multinasional Indonesia.

Dyanty, Vera., Sidharta Utama., Hila Rosietta dan Sylvia Veronica, 2011. Pengaruh Kepemilikan Pengendali Akhir Terhadap Transaksi Pihak Berelasi.

Eisenhardt, K. M. (1989). Agency Theory: An Assessment and Review Linked references are available on JSTOR for this article: Agency Theory: An Assessment and Review, 14(1), 57-74.

Fatmariani. (2013). Pengaruh Struktur Kepemilikan, Debt Covenant Dan Growth Opportunities Terhadap Konservatisme Akuntansi Pada Perusahaan Manufaktur Yang Terdaftar Di Bursa Efek Indonesia.

Ghozali, Imam. 2018. Aplikasi Analisis Multivariate dengan Program IBM SPSS 25. Semarang: Badan Penerbit Universitas Diponegoro.

Harahap, Sherly Noviana. (2012). Peran Struktur Kepemilikan, Debt Covenant, dan Growth Opportunities terhadap Konservatisme Akuntansi. Jurnal Ilmiah Mahasiswa AkuntansiVol.1, No. 2

Hartati, Winda. Desmiyawati. Julita. (2014). Tax Minimization, Tunneling Incentive dan Mekanisme Bonus terhadap Keputusan Transfer Pricing Seluruh Perusahaan yang Listing di Bursa Efek Indonesia.

Horngren, T, Charles, Srikant M, Datar, dan George Foster. 2008. Akuntansi Biaya: Dengan Penekanan Manajeria. Jakarta: Erlangga.

Ikatan Akuntan Indonesia, 2015. Standar Akuntansi Keuangan, PSAK No. 19 Pasal 17, PSAK No. 7 , PSAK No. 24.

Irpan, 2011. Analisis Pengaruh Skema Bonus Direksi, Jenis Usaha, Profitabilitas Perusahaan dan ukuran Perusahaan terhadap Erning Management.

Irpan. 2010. Analisis Pengaruh Skema Bonus Direksi, jenis Usaha, Profitabilitas Perusahaan, dan Ukuran Perusahaan Terhadap Earning Management: Studi Empiris Pada Perusahaan 
Pengaruh Profitabilitas, Pajak, Mekanisme Bonus, Kepemilikan Asing, Debt Covenant Dan Intangible Assets Terhadap Transfer Pricing (Studi Empiris Pada Perusahaan Manufaktur Yang Terdaftar Di Bei Tahun 2015 - 2017)

Manufaktur dan Keuangan yang Listing Di BEI Paada Tahun 2008-2010. Skripsi. Fakultas Ekonomika dan Bisnis. UIN Syarif Hidayatullah. Jakarta.

Jensen, M. C., \& Meckling, W. H. (1976). Theory of the Firm: Managerial Behavior, Agency Costs and Ownership Structure.

Klassen, K. J. (2017). Transfer Pricing: Strategies, Practices, and Tax Minimization, 34(1), 455-493. https://doi.org/10.1111/1911-3846.12239

Mangoting, Y. (2000). Aspek perpajakan dalam praktek transfer pricing, 2, 69-82.

Mispayanti. 2015. Pengaruh Pajak, Tunneling Incentive, dan mekanisme Bonus Terhadap Keputusan Transfer Pricing. Jurnal Akuntansu dan Investasi, 16(1).

Narulita, Selly (2017). Pengaruh Pajak, Bonus Plan dan Kepemilikan Asing terhadap Keputusan Perusahaan Melakukan Transfer Pricing.

Nuradila, F. N, dan Wibowo, R. A. Tax Minimization Sebagai Pemoderasi Hubungan Antara Tunneling Incentive, Bonus Mechanism dan Debt Covenant dengan Keputusan Transfer Pricing.

OECD committee on Fiscal Affairs. 2015. Transfer Pricing Guidelines for Multinational Enterprise. OECD. Paris.

Pemerintah Indonesia. 2007. Undang-Undang Nomor 25 Tahun 2007 pasal 1 ayat (6) tentang Penanaman Modal

Pemerintah Indonesia. 2008. Undang-Undang No. 36 Tahun 2008 tentang Transfer Pricing.

Pemerintah Indonesia. 2009. Undang-Undang Nomor 16 Tahun 2009 Tentang Ketentuan Umum Dan Tata Cara Penerapa Pajak.

Pemerintah Indonesia. 2009. Undang-Undang Nomor 42 Tahun 2009 tentang Hubungan Istimewa.

PMK No. 213/PMK.03/2016 tentang Transfer Pricing.

Pohan, C.A. 2016. Perpajakan : Strategi Perencanaan Pajak dan Bisnis. Jakarta : PT GRAMEDIA

Pramana, 2014. Pengaruh Pajak, Bonus Plan, Tunneling Incentive, dan Debt Covenant Terhadap Keputusan Perusahaan Untuk Melakukan Transfer Pricing.

Purwanti, L. 2010. Kecakapan Managerial, Skema Bonus, Manajemen Laba, dan Kinerja Perusahaan. Jurnal Aplikasi Manajemen. 8(2).

Putri, F. N. (2014). Pengaruh karakteristik kepemilikan dan kompensasi eksekutif terhadap tax aggressive. Padang.

Rosa, Ria. Andini, Rita. Raharjo, Kharis (2017). Pengaruh Pajak, Tunneling Incentive, Mekanisme Bonus, Debt Covenant, dan Good Corporate governance (GCG) Terhadap Transaksi Transfer Pricing.

Saifudin. Putri, Luky Septiani. (2018). Determinasi Pajak, Mekanisme Bonus, Dan Tunneling Incentive Terhadap Keputusan Transfer Pricing Pada Emiten BEI 2(1), 32-43. https://doi.org/10.22236/agregat

Sari, E. P., \& Mubarok, A. (2018). Pengaruh Profitabilitas, Pajak dan Debt Covenant Terhadap Transfer Pricing ( Studi Empiris Perusahaan Manufaktur Terdaftar di BEI Tahun 2012-2016 ).

Silalahi, A. D. Dkk . 2018. Manajemen Perpajakan. Medan : MADENATERA.

Suandy, Erly. 2011. Perencanaan Pajak. Edisi 6. Penerbit Salemba Empat. Jakarta.

Sukma, Suci Asral. (2018). Pengaruh Pajak, Tunneling Incentive, Mekanisme Bonus Dan Kepemilikan Asing Terhadap Transfer Pricing , 1, 1-15.

Suryatiningsih, Neneng dan Sylvia Veronica Siregar. 2009. Pengaruh Skema Bonus Direksi Terhadap Aktivitas Manajemen Laba: Studi Empiris Pada BUMN Periode Tahun 2003-2006. Jurnal Simposium Nasional Akuntansi 11.

Tamba, Erida Gabriella Handayani. (2011). Pengaruh Struktur Kepemilikan Terhadap Pengungkapan Tanggung Jawab Sosial Perusahaan.

Tiwa, Evan Maxentia. Saerang, David P E. Victorina Z Tirayoh. (2017). Pengaruh Pajak Dan Kepemiliksn Asing Terhadap Penerapan Transfer Pricing Pada Perusahaan Manufaktur Yang Terdaftar DI BEI Tahun 2013-2015, 5(2), 2666-2675. 